resistance to CL was not useful to predict REA type, as these 10 strains were of 4 different REA types.

In our study, the discriminatory index of the antibiogram was 0.78 for MRSA, a much lower value than the index of 0.98 reported by Struelens et al. ${ }^{8}$ In part, this is because of a difference in the criteria used for typing. In their study, isolates showing only one major difference (R-S or SR) or one minor difference (R-I, I-R, S-I, I-S) in susceptibility to one or more agents were considered as distinct strains. In contrast, with the criteria proposed by Tenover, ${ }^{4}$ the isolates showing dissimilar resistance patterns to at least two or more agents were considered as different. We used an empirical hybrid method using the predominant pattern and key markers, as described in "Methods."

The genotyping discriminatory index of 0.56 for MRSA in our study is also lower than that found in Struelens' report $(0.96) .{ }^{8}$ This is probably because our isolates were obtained from an endemic SNF setting where most strains likely represented relatively few clones, ${ }^{16,17}$ not from widely separated hospitals, and may also be due to different geographical locations and settings.

In conclusion, our study demonstrated that, in MRSA isolates colonizing patients from one community SNF, genotyping by FIGE REA identified two prevalent REA types, but with some variability of antibiogram patterns within each REA type; and that practical typing by antibiogram phenotype patterns also identified prevalent patterns, but there was some variability in REA types found within many of these antibiogram patterns. Because of the predominance of two REA types in this SNF, the discriminatory ability of genotypes as determined by FIGE REA and of antibiogram typing, as calculated by the Discriminatory Index, was less than reported for MRSA isolated from different acute-care hospitals. ${ }^{8}$

\section{REFERENCES}

1. Boyce JM. Increasing prevalence of methicillin-resistant Staphylococcus aureus in the United States. Infect Control Hosp Epidemiol 1990;11:639642.
2. Bradley SF, Terpenning MS, Ramsey MA, Zarins LT, Jorgensen KA, Sottile WS, et al. Methicillin-resistant Staphylococcus aureus: colonization and infection in long-term care facility. Ann Intern Med 1991;115:417-422.

3. Goering RV, Winters MA. Rapid method for epidemiological evaluation of gram-positive cocci by field inversion gel electrophoresis. $J$ Clin Microbiol 1992;30:577-580.

4. Tenover FC, Arbeit R, Archer G, Biddle J, Byrne S, Goering R, et al. Comparison of traditional and molecular methods of typing isolates of Staphylococcus aureus. J Clin Microbiol 1994;32:407-415.

5. National Committee for Clinical Laboratory Standards. Performance Standards for Antimicrobial Disc Susceptibility Tests. 4th ed. Approved Standard M2-A4. NCCLS: Villanova, PA; 1990.

6. Hunter PR Reproducibility and indices of discriminatory power of microbial typing methods. J Clin Microbiol 1990;28:1903-1905.

7. Blanc DS, Petignat C, Moreillon P, Wenger A, Bille J, Francioli P. Quantitative antibiogram as a typing method for the prospective epidemiological surveillance and control of MRSA: comparison with molecular typing. Infect Control Hosp Epidemiol 1996;17:654-659.

8. Struelens MJ, Deplano A, Godard C, Males N, Serruys E. Epidemiological typing and delineation of genetic relatedness of methicillin-resistant Staphylococcus aureus by macrorestriction analysis of genomic DNA by using pulsed-field gel electrophoresis. J Clin Microbiol 1992;30:2599-2605.

9. Archer GL, Mayhall CG. Comparison of epidemiologic markers used in the investigation of an outbreak of methicillin-resistant Staphylococcus aureus infections. J Clin Microbiol 1983;18:395-399.

10. Mulligan ME, Kwok RY, Citron DM, John JF Jr, Smith PB. Immunoblots, antimicrobial resistance, and bacteriophage typing of oxacillin-resistant Staphylococcus aureus. J Clin Microbiol 1988;26:2395-2401.

11. Blanc DS, Lugeon C, Wenger A, Siegrist HH, Francioli P. Quantitative antibiogram typing using inhibition zone diameters compared with ribotyping for epidemiological typing of methicillin-resistant Staphylococcus aureus. J Clin Microbiol 1994;32:2505-2509.

12. Swaminathan B, Matar GM. Molecular typing methods: definition, applications, and advantages. In: Persing DH, Smith TF, Tenover FC, White TJ, eds. Diagnostic Molecular Microbiology: Principles and Applications. Washington, DC: American Society for Microbiology; 1993:26-50.

13. Arbeit RD. Laboratory procedures for the epidemiological analysis of microorganisms. In: Murray PR, Baron EJ, Pfaller MA, Tenover FC, Yolken RH, eds. Manual of Clinical Microbiology. 6th ed. Washington, DC: American Society for Microbiology; 1995:190-208.

14. Hall IM. Are point mutations or DNA rearrangements responsible for the restriction fragment length polymorphisms that are used to type bacteria. Microbiology 1994;140:197-204.

15. Maslow JN, Mulligan ME, Arbeit RD. Molecular epidemiology: application of contemporary techniques to the typing of microorganisms. Clin Infect Dis 1993;17:153-164.

16. Zuccarelli AJ, Roy I, Harding GP, Comperus JJ. Diversity and stability of restriction enzyme profiles of plasmid DNA from methicillin-resistant Staphylococcus aureus. J Clin Microbiol 1990;28:97-102.

17. Kreiswirth B, Kornblum J, Arbeit RD, Eisner W, Maslow JN, McGeer A, et al. Evidence for a clonal origin of methicillin resistance in Staphylococcus aureus. Science 1993;259:227-230.

\title{
Epidemic of Pneumonia Associated With Mechanical Ventilation
}

\section{Gina Pugliese, RN, MS Martin S. Favero, $\mathbf{P h D}$}

Dr. Mussaret Zaidi and colleagues from the Departamento de Investigacion, Hospital General O'Horan, Merida, Yucatan, Mexico, conducted a study to determine the main epidemiological, clinical, and microbiological characteristics of an outbreak of ventilator-associated pneumonia at an ICU in Yucatan. An 11month prospective and observational study was designed to determine inci- dence, mortality, potential reservoirs, etiologic agents, and antibiotic susceptibility patterns.

The incidence of ventilator-associated pneumonia was $74 \%$. The crude mortality rate was $88 \%$ compared to a $19.5 \%$ expected mortality rate. Gram-negative bacteria were isolated from $98 \%$ of the cultures, of which $46 \%$ were susceptible to thirdgeneration cephalosporins, $59 \%$ to fourth-generation cephalosporins, $70 \%$ to ciprofloxacin, and $100 \%$ to imipenem. Klebsiella pneumoniae and Pseudomonas aeruginosa were isolat- ed from some of the ventilator circuits and the sink.

It was concluded that the high incidence of pneumonia and associated mortality in our ICU may be attributed to the absence of infection control measures and the high prevalence of multiresistant organisms, which is related to antibiotic abuse.

FROM: Zaidi M, Martin G, Rosado R. Epidemic of pneumonia associated with mechanical ventilation in Merida, Yucatan. Salud Publica Mex 1999;41(suppl 1):S38-S43. 